\section{Research on grassland ecosystem service value in China under climate change based on meta-analysis: a case study of Qinghai province}

\author{
Binyue Kang, Qiuyu Shao, Hengkang Xu, Fengyan Jiang, \\ Xiaoting Wei and Xinqing Shao \\ (Author affiliations can be found at the end of the article)
}

Grassland ecosystem service value in China

Received 30 June 2020 Revised 19 August 2020 Accepted 20 August 2020

\begin{abstract}
Purpose - Grassland in Qinghai as the main type of ecosystem in this region is located in arid and semi-arid areas. The ecosystem is fragile and sensitive to climate change. Grassland ecosystem not only provides essential ecological and life functions for human society but also plays a vital role in mitigating and adapting to climate change. The empirical literature on grassland ecosystem services value (ESV) does not consider the impact of climate change and regional economic development level factors, which prevents policymakers from making appropriate decisions. This paper aims to analyze the influencing factors of grassland ESV assessment, and, based on the meta-prediction model, account the grassland ESV in Qinghai province.

Design/methodology/approach - To understand the value of grassland ecosystem services in China under climate change, this paper used 61 research literature on the evaluation of grassland ESV in China, including a total of 564 value observations to establish a value transfer database. Based on the meta-analysis method, this study has
\end{abstract}

(C) Binyue Kang, Qiuyu Shao, Hengkang Xu, Fengyan Jiang, Xiaoting Wei and Xinqing Shao. Published by Emerald Publishing Limited. This article is published under the Creative Commons Attribution (CC BY 4.0) licence. Anyone may reproduce, distribute, translate and create derivative works of this article (for both commercial and non-commercial purposes), subject to full attribution to the original publication and authors. The full terms of this licence may be seen at http:// creativecommons.org/licences/by/4.0/legalcode

Author contributions: Binyue Kang and Qiuyu Shao contributed equally to this work.

Funding: This work was supported by the Ministry of Science and Technology of China (Grant No. 2016YFC0501902), the National Natural Science Foundation of China (Grant No. 31971746), the Major Science and Technology Project in Qinghai Province (2018-NK-A2), and Platform of Adaptive Management on Alpine Grassland-livestock System (Grant No. 2020-ZJ-T07).

Erratum: It has come to the attention of the publisher that the article, "Research on grassland ecosystem service value in China under climate change based on meta-analysis: a case study of Qinghai province" published in International Journal of Climate Change Strategies and Management, Vol. 12 No 5 by Binyue Kang, Qiuyu Shao, Hengkang Xu, Fengyan Jiang, Xiaoting Wei and Xinqing Shao, (2020), omitted to include the funding provider: Ministry of Science and Technology of China (Grant No. 2016YFC0501902), the National Natural Science Foundation of China (Grant No. 31971746), the Major Science and Technology Project in Qinghai Province (2018-NK-A2), and Platform of Adaptive Management on Alpine Grasslandlivestock System (Grant No. 2020-ZJ-T07) and the author affiliation for Qiuyu Shao was printed incorrectly. These errors were introduced in the editorial process and have now been corrected in the online version. The publisher sincerely apologises for this error and for any inconvenience caused.

This paper forms part of special section "Climate change impacts and adaptations in arid and semi-arid regions", guest edited by Zhihua Zhang, Qiang Zhang and Muhammad Jawed Iqbal.

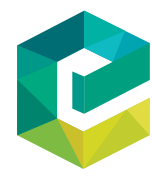

International Journal of Climate Change Strategies and Management po. 6,2020
pp. $617-637$

pp. $617-637$
Emerald Publishing Limited 1756-8692 DOI 10.1108/IJCCSM-06-2020-0073 
IJCCSM 12,5

618 constructed a value transfer model, to evaluate the grassland ESV in Qinghai province, and an interpretation model, which can analyze if the independent variables affect the grassland ESV significantly.

Findings - The study finds that the evaluation methods, types of ecosystem service functions, climate change and grassland types can affect the grassland ESV significantly. Based on the meta-regression prediction model to evaluate the grassland ESV in Qinghai is US $\$ 1,542.67 /$ ha/year. It indicates several targeted approaches to increase the grassland ESV, and climate change also has a specific impact on the value of grassland ecosystem services.

Research limitations/implications - This study provides a scientific basis for grassland management related to the development of grasslands and ecological compensation, as well as promote the sustainable development of grassland ecosystems.

Originality/value - This paper contributes to the field of grassland ESV assessment in at least three aspects; first, it innovatively introduces the meta-analysis to carry out an integrated analysis of previous research results; second, it includes a broader set of influence variables in the analysis, including meteorological and economic factors; and third, it establishes a methodological basis for the field of grassland ESV accounting.

Keywords Climate change, Grassland ecosystem, Ecosystem service value, Value transfer, Meta-analysis

Paper type Research paper

\section{Introduction}

Climatic changes have been identified as one of the most critical drivers of change in ecosystems and their services (Millenium Ecosystem Assessment, 2005; Nelson et al., 2013). IPBES (Intergovernmental Science-Policy Platform on Biodiversity and Ecosystem Services, 2019) assessed direct drivers of change for ecosystem function and structure and showed that climate change is among the top drivers for any ecosystem realm. Bagstad et al. (2013) expected that continued climate change would reduce the water supply in arid and semi-arid areas and have a negative impact on water quality. Massive changes in climate and land use typically resulted in significant changes in ecosystem service supply. Some of these trends may be positive (for example, increases in forest area and productivity); some of the changes may increase vulnerability as a result of a decreasing supply of ecosystem services (Schirpke et al., 2017; Schroter et al., 2005).

Ongoing climate change is a critical factor impacting the growth of grassland vegetation (Tao et al., 2015). Therefore, research on the management and development of grassland ecosystems is inseparable from climate change. As the main type of ecosystem in Qinghai province, an arid and semi-arid region with the extraordinarily harsh and fragile ecological environment, the grassland plays an essential role in maintaining the ecological balance of the earth biosphere and global climate change (Du and Yu, 2018; Sándor and Domşa, 2018), and has significant environmental benefits and economic value (Kolstad, 2000). Many researchers have studied how climate factors influence the grassland ecosystem. Maalouf et al. (2012) believe that drought events impact plant diversity of mesic and xeric calcareous grassland communities. Tao et al. (2015) reveal higher climate sensitivity in higher elevation areas of the plateau. Little research has focused on the direct analysis of how climate change influences grassland ecosystem service value.

Ecosystem services are the conditions and processes through which natural ecosystems, and the species that make them up, sustain and fulfill human life (Cairns, 1997; Costanza et al., 1997; Daily, 1997; Millenium Ecosystem Assessment, 2005). After calculation, the total value of global ecosystem services is as high as $\$ 33 \mathrm{tn}$ per year, which is about twice the global GDP (Costanza et al., 1997). At the grassland ecosystem level, Costanza et al. (1997) select nine types of grassland ecosystem services, such as runoff regulation, gas regulation, soil formation and soil erosion control, to calculate the total service value of US\$906bn per 
year. Based on the methodology proposed by Costanza, Xie et al. (2003) also divided the national grassland ecosystem into 18 categories and 21 subcategories. The results of the study indicate that the unit area ESV of grassland in the country was 5,354.32 (US\$/ha/ year). Although the connections between climate changes and their impacts on the grassland ESV are yet not well understood, both the government and researchers recognize the importance of grassland ecosystems in mitigating and responding to climate change (Watson et al., 2020; Ning et al., 2019; Sala et al., 2017). In the top-level design of the grassland areas such as the "13th Five-Year Plan for National Grassland Protection and Construction and Utilization" and "Planned Grassland, Grassland, Rivers, and Lakes Rest and Recreation Plan (2016-2030)," more attention is paid to global climate change. However, how to achieve the economic point of view of the "Pareto optimal" (Kolstad, 2000) allocation of resources is of great significance. Thus, accounting for the grassland ESV is an integral part of it.

Different researchers have different views on the heterogeneity characteristics of grassland, and the value of ecological services provided by different grassland types is also different (Gao and Lin, 2014). Therefore, we need a strict and objective statistical method: meta-analysis to integrate the previous research results and get rigorous research conclusions (Brander et al., 2012). The benefit transfer based on meta-regression can effectively control the differences of various factors, such as the characteristics of the research object, background and method, to obtain precise and accurate transfer results, and also perform better in practical applications (Duarte et al., 2018; Fleiss and Gross, 1991; Johnston and Rosenberger, 2010; Moeltner et al., 2007; Salem and Mercer, 2012). However, there is not much research on the ESV accounting in China using meta-analysis methods (Table 1), and it is still negligible for the field of grassland ecosystems.

At present, few studies use meta-analysis to evaluate the grassland ESV in China, and the relationship between grassland ecosystem services and climate change is still unclear. This paper aims to conduct a systematic analysis of what factors influence grassland ESV in China and obtain objective grassland ESV in Qinghai province based on the metaanalysis utility transfer method. The research results hope to provide a scientific basis for grassland management; raise eco-friendly awareness among developers and policymakers; avoid short-sighted economic behavior that damages grassland ecosystems; and ultimately promote the sustainable development of grassland ecosystems.

\section{Methodology}

\subsection{Study area}

The grassland ecosystem accounts for $50.9 \%$ of the Qinghai-Tibet Plateau, which is a sensitive
area of climate change and an ecologically fragile zone (Du and Yu, 2018; Xie et al., 2003). It is

The grassland ecosystem accounts for $50.9 \%$ of the Qinghai-Tibet Plateau, which is a sensitive
area of climate change and an ecologically fragile zone (Du and Yu, 2018; Xie et al., 2003). It is

\begin{tabular}{lll}
\hline Methodology & Ecosystem/ESV function & Author/Year \\
\hline Use meta-analysis & Recreational value & Zhao and Wang, (2013) \\
methods to gather & Lake and marsh ESV & Zhang et al., (2015) \\
previous research & Biodiversity value & Zhou et al., (2016) \\
results and access the & Urban ESV & Zhang et al., (2016) \\
value transfer of & Wetland ESV & Yang et al., (2017) \\
ecosystem services & Inland River Basin ESV & Yan et al., (2017) \\
& Resource-based city ESV & Zhu et al., (2017) \\
& Forest ESV & Qi et al., (2018) \\
& Wetland ESV & Sun et al., (2018) \\
& Wetland ESV & Li et al., (2018) \\
& Water Resources value & Xu et al., (2019)
\end{tabular}

Grassland ecosystem service value in China

619
Table 1. Meta-analysis of studies to assess the ESV in the field of Chinese scholars have used 
IJCCSM

12,5

620

an ideal place to study the response mechanism of grassland ecosystems to climate change. The study site for this paper is in Qinghai province $\left(89^{\circ} 35^{\prime}-103^{\circ} 04^{\prime} \mathrm{E}, 31^{\circ} 40^{\prime}-39^{\circ} 19^{\prime} \mathrm{N}\right)$, which is located in the northeast of the Qinghai-Tibet Plateau (Figure 1). Qinghai province connects Qilian Mountain and Altun Mountain in the north, Animaqing Snow Mountain and Kunlun Mountain in the middle and Bayan Hara Mountain and Tanggula Mountain in the south, showing the complex and diverse landforms. Qinghai province, as one of the five largest pastoral areas in China, has the fourth largest grassland area in the country, with a total area of $4.034 \times 10^{7} \mathrm{~h} \mathrm{~m}^{2}$, of which $78.36 \%$ are available grasslands. Because of the complex topography and landforms, there are nine major categories and seven subcategories of grasslands in Qinghai province. Among them, alpine meadows and alpine grasslands are the main subjects, accounting for $60.9 \%$ of the total area.

\subsection{Meta-regression model}

Referring to the method used by Bergstrom and Taylor (2006), Brander et al. (2012), Chaikumbung et al. (2016) and Salem and Mercer (2012) and combining the characteristics of grassland ecosystem services studied in this paper, a meta-model, equation (1), is built. The numerical variables (e.g. grassland area, annual temperature) in this study are included in the model in the form of natural logarithms, which can reduce the fluctuation of the original data (but cannot be eliminated), improve the accuracy of model fitting and reduce heteroscedasticity (Ghermandi et al., 2010).

$$
\ln \left(y_{i}\right)=a+b_{\alpha} X_{\alpha}+b_{\beta} X_{\beta}+b_{\gamma} X_{\gamma}+b_{\delta} X_{\delta}+b_{\omega} X_{\omega}+b_{\mu} X_{\mu}+b_{\lambda} X_{\lambda}+\varepsilon
$$

In equation (1), the dependent variable $y_{i}$ is the value vector of each ecological service function of the grassland ecosystem (unit: US\$/ha/year, the value of ecosystem services per

Figure 1. Location of the study area

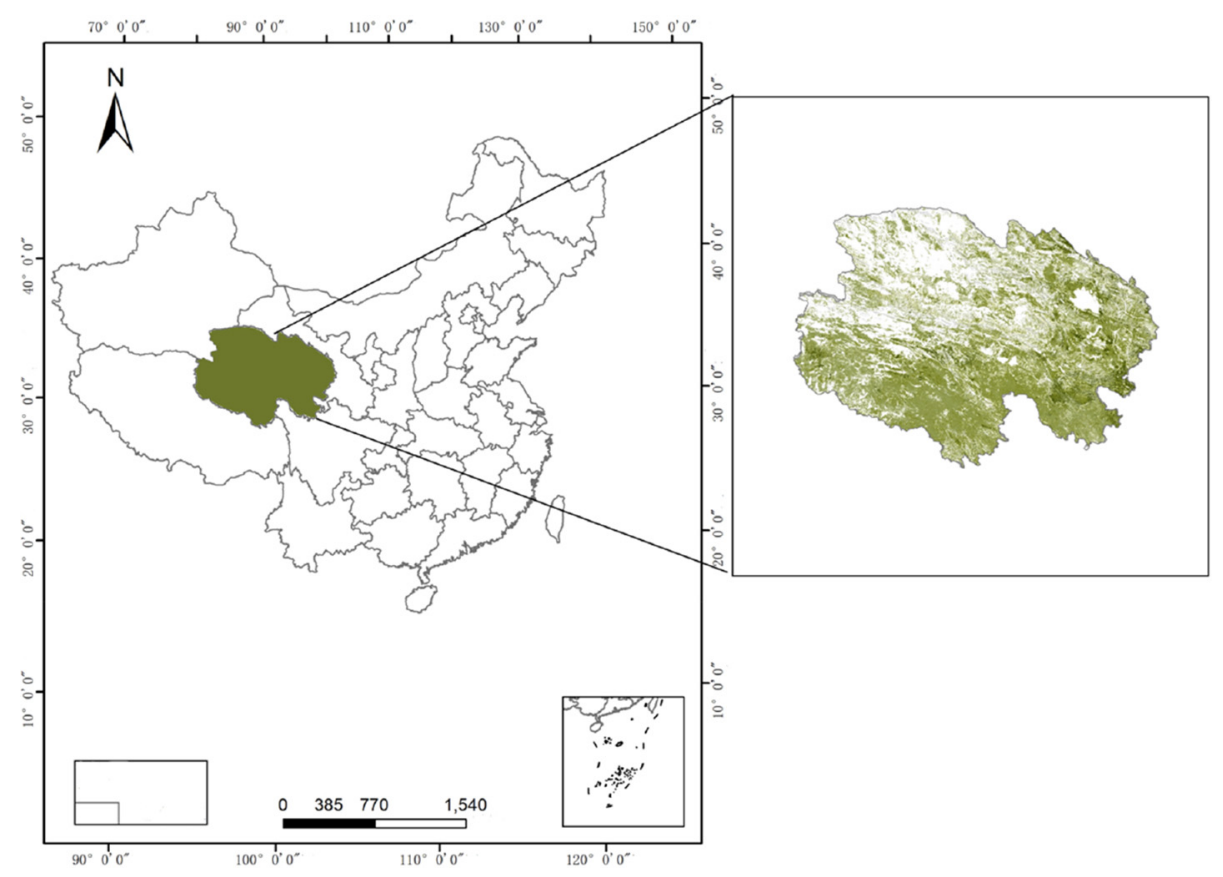


unit area per year), which has been adjusted to the value basing in 2019 by the consumer price index. $a$ is a constant term; $\varepsilon$ is a vector of residual error distributed as a multivariate normal distribution with zero means and unitary variance; $b_{\alpha \sim \lambda}$ are the matrix of unknown regression coefficients; and $X_{\alpha \sim \lambda}$ are independent variable matrices. $X_{\alpha}$ is the evaluation methods variable matrix, $X_{\beta}$ is the matrix of ecosystem service function type, $X_{\gamma}$ is the grassland characteristic matrix, $X_{\delta}$ is the matrix of the economic development status, $X_{\omega}$ is the matrix of the grassland region and $X_{\mu}$ and $X_{\lambda}$ are matrices of meteorological factors, representing temperature and rainfall, respectively.

In the domestic and foreign researches on the value prediction method based on metaregression analysis to calculate the ESV, the choice of multiple linear regression method focuses on the use of the weighted least square (WLS) method (Li et al., 2018; Yan et al., 2019; Yang et al., 2017) and backward elimination method (Salem and Mercer, 2012; Zhu et al., 2017). WLS is a method of weighting based on the existing model, and then using least squares to perform the regression (Garson, 2013), which can effectively reduce heteroscedasticity, but the determination of weights also has an impact on the accuracy of the result fitting. Choose the appropriate weights; weighting the number can reasonably reduce heteroscedasticity. Rosenberger and Loomis (2001) used the reciprocal of the square root of the sample size as the weight, and Ghermandi et al. (2010) and Salem and Mercer (2012) used the reciprocal of the observations provided by each source document in the meta-database as the weight to weight the model. The research results of Hedges $e t$ al. (1999) indicate that the optimal weight in the WLS method should be the reciprocal of the variance. Because it is expected to provide further weight to the observations with higher evaluation accuracy, we use the reciprocal of the variance as weight in this study. We obtain the weights in SPSS 23.0 according to the method introduced by Garson (2013). The backward elimination method is to calculate the partial correlation coefficient between the independent variable and the dependent variable and to eliminate the independent variables with the smallest partial correlation coefficient and the $F$ value that does not meet the standard until all the independent variables in the model meet the standard. The final equation is the optimal equation for the fitting effect. This study will build two models based on WLSs and backward elimination methods, compare their fitting accuracy and select models with higher fitting accuracy for independent variable interpretation and value transfer.

\subsection{Validity test}

Although the meta-regression analysis method has many advantages mentioned above, in the process of value transfer using the meta-regression model, substantial errors may still occur, which are called transfer errors. It is essential to test the validity, referred to as the validity test. We test the validity of the prediction model according to the following four methods.

2.3.1 Paired-samples t-test. Based on statistical assumptions, at a significance level of 0.05 , whether the predicted value of the meta-prediction model is different from the actual observed value, that is, whether it is significantly different, is determined, and then the hypothesis is accepted or rejected. In this study:

$$
\begin{aligned}
& H_{0}: \mu_{0}=0 \\
& H_{1}: \mu_{0} \neq 0
\end{aligned}
$$

where $\mu_{0}$ is the difference between the predicted value and the real value, the statistic $t=\frac{\bar{D}-u_{0}}{S_{D} / \sqrt{n_{p}-1}}, \bar{D}$ is the average of the difference between the predicted value and real value and $S_{D}$ is the difference between the paired samples the standard deviation of value. 
IJCCSM 12,5

2.3.2 Pearson correlation coefficient test. To show the correlation degree and trend between the two variables, we introduce the concept of Pearson correlation coefficient. If the correlation coefficient is significant, it indicates that the predicted value is significantly correlated with the observed value.

2.3.3 Error test. According to the method introduced by Rosenberger and Loomis (2001), we use the mean complete percent error (MAPE) to test the prediction model's validity. Existing studies generally accept the acceptable range of $20 \%-40 \%$ given by Brander et al. (2012).

$$
\mathrm{MAPE}=\left|\left(Y_{o b s}-Y_{\text {pred }}\right) / Y_{o b s}\right|
$$

In equation (2), $Y_{\text {obs }}$ is the actual value of grassland and $Y_{\text {pred }}$ is the predicted value of grassland ESV predicted by meta-model.

2.3.4 Linear regression test. A linear regression between the predicted value and the observed value is performed to obtain the correlation coefficient $\beta$ and the constant term $\alpha$ of equation (3). If $\alpha=0, \beta=1$ and the $p$-values are under 0.05 , it means that statistics and predictions are approximately the same. The above two hypothesis tests are conducted with $t$-test and $F$-test, respectively.

$$
\ln \left(y_{i}\right)=\alpha+\beta \ln \left(\hat{y}_{i}\right)+\varepsilon
$$

\section{Data and estimation scheme}

\subsection{Data source and processing}

Data were collected from the Web of Science and the Chinese National Knowledge Infrastructure (CNKI) databases before January 1, 2020. When searching for articles related to grassland ESV, the following keyword were used: "ecosystem service value," "grassland," "rangeland" and "ESV." A total of 1,104 documents were retrieved, of which 325 were Chinese documents, and 779 were English documents. To minimize publication bias, documents with the following four conditions will be excluded:

(1) The research object is artificial grassland or artificial green space.

(2) The study site is outside of China.

(3) The type of assessment grassland is not classified, or the classification standard is unreasonable.

(4) The accounting method is energy analysis.

According to the above conditions, we filtered to get a total of 564 value observations in 61 related literature. Among the documents that meet the requirements, 48 are journal articles and 13 master's and doctoral theses, 57 of which are Chinese documents and 4 are English documents. As per statistics from the time scale, the earliest publication time was in 2001, 11 articles were published in 2001-2005, 15 articles were published in 2006-2010 and 35 articles were published after 2010. We use Get Data Graph Digitizer v2.26 to extract data from document charts and establish the meta-analysis value transfer database. Figure 2 shows that the sample cases in the database are distributed in 12 provinces across the country, with even distribution and broad types. Therefore, they can reflect the differences in social economy and grassland types in the process of calculating the grassland ESV. In particular, Qinghai, Tibet and Inner Mongolia account for a relatively large proportion, which is related to the geographical distribution pattern of grassland resources in China. 


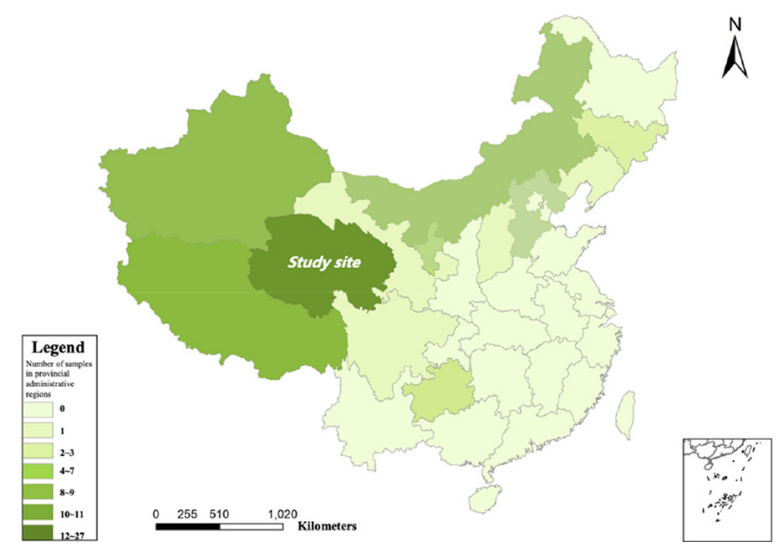

Grassland ecosystem service value in China

Figure 2.

Geographical distribution of sample cases

In the meta-database of this study, the research time of different literature is various, and the obtained results have currency time differences. Therefore, to make the data comparable, we adjust research results to the value level of 2019 and use US\$ as the unit of ESV. We use Excel 2016 to perform fundamental descriptive statistical analysis of the sample, and SPSS 23.0 and $\mathrm{R}$ 4.0.0 to perform regression analysis and data visualization.

\subsection{Descriptive statistical analysis of samples in the database}

3.2.1 Comparing ecosystem services value differences of grassland ecosystem in China. Figure 3 shows the average value distribution of various ecosystem service types in China's grassland ecosystem. As shown in the figure, the average value of various ecosystem services presents a specific difference. Among them, the function with the highest value is the carbon fixation and oxygen release. The average value of the database is 538.91 (US\$/ha/ year) and the function with the lowest value is the grass products. The average value in the

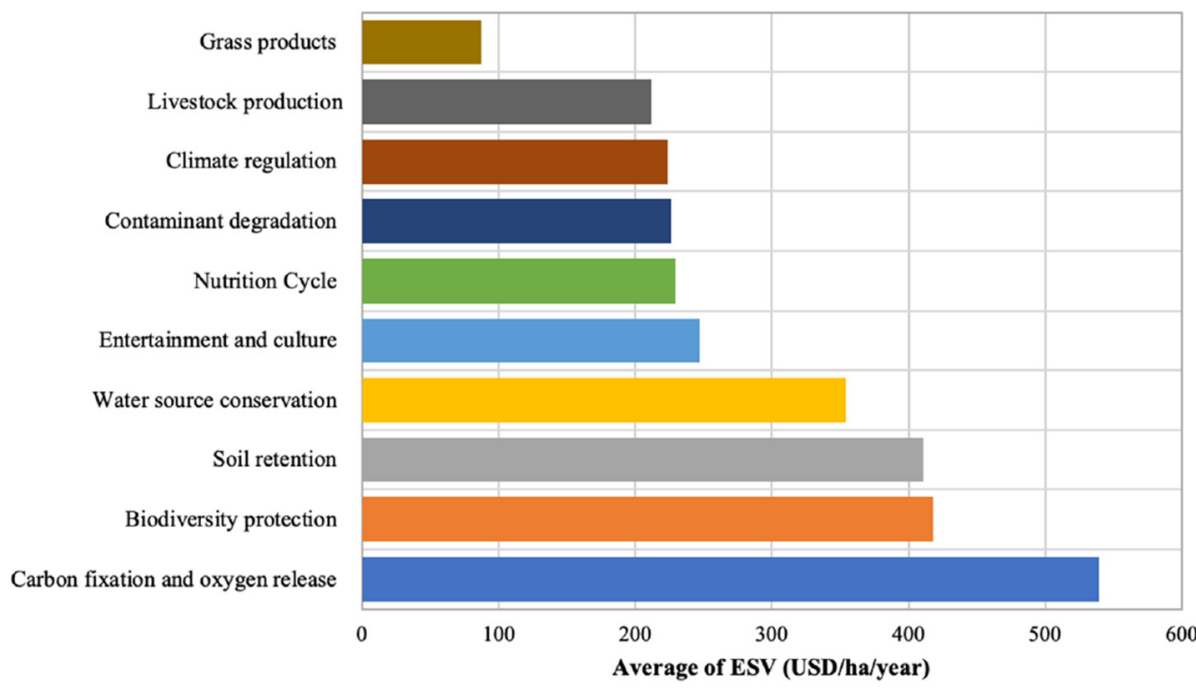

Figure 3.

Average value of grassland ecosystem service function in the meta-database 
IJCCSM

12,5

624 database is 87.45 (US\$/ha/year). It is not comprehensive to only compare the mean value of each service function of the grassland ecosystem, and only the overall trend can be obtained. If the research analyzes whether the differences in various service functions of the grassland ecosystem are significant, which needs subsequent data analysis, so we introduce the interpretation equation to analyze and explain each class variables.

Figure 4 shows that the functional ESV of grassland is evenly distributed, which reflects the rationality of the meta-database and lays the foundation for subsequent data analysis.
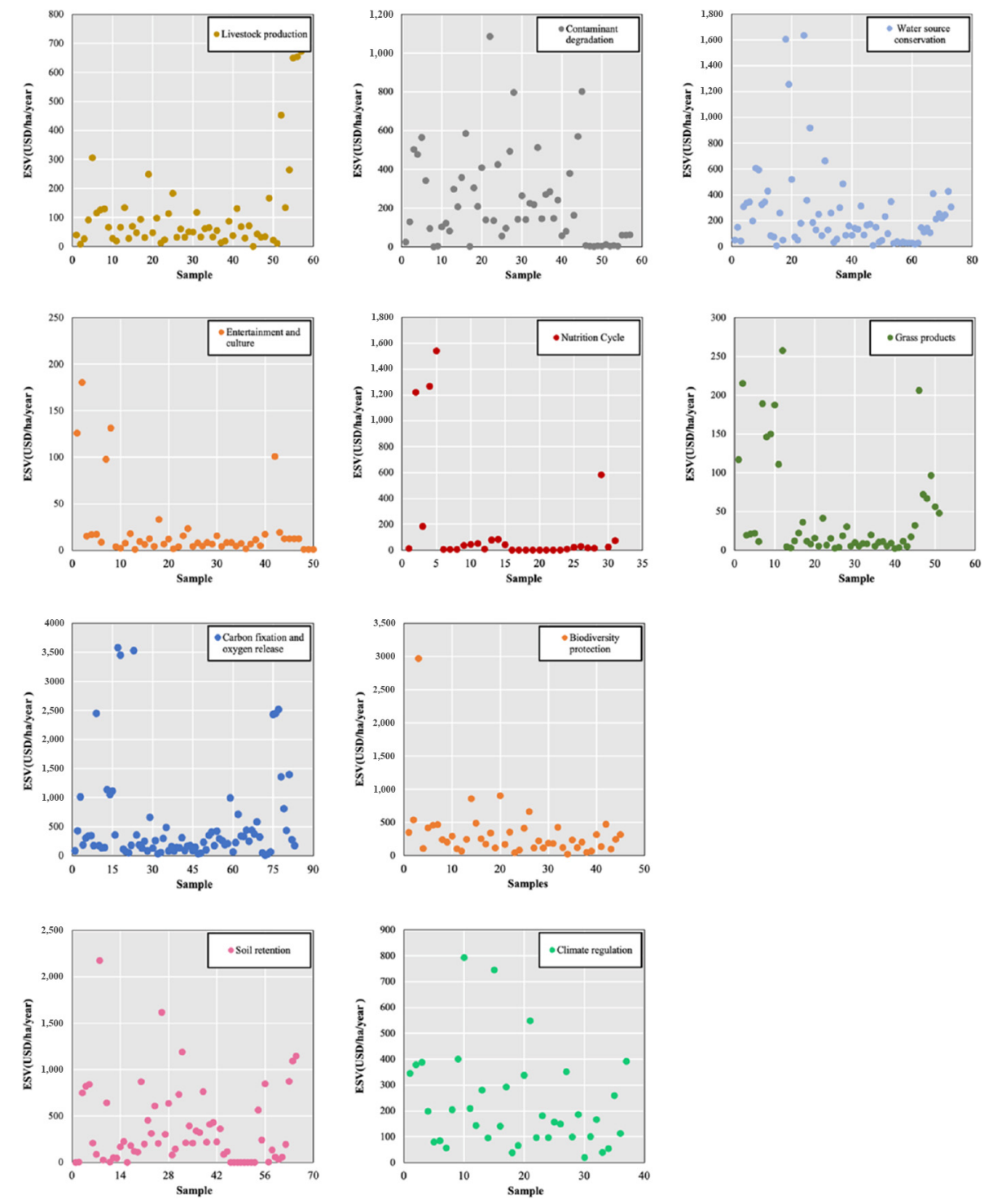

Figure 4.

Distribution of each grassland function's ESV in the sample 
Compared with Figure 3, the scatter chart can reflect the details of the value of each ecological service function, which cannot be reflected from the average statistics. We check the singular values of the observations in the sample and trace the reasons. For example, it can be found that in the biodiversity protection function, the value calculated by the opportunity cost method is too high. This is because the accounting method results in a high value of the accounting value. Therefore, the accounting method should be included in the model as one of the independent variables in the subsequent modeling (Johnston and Rosenberger, 2010). Because of the difference in the productivity of grassland resources, if the productivity of undegraded grassland is higher than that of degraded grassland, the productivity of meadow grassland is also higher than that of desert grassland (Miller et al., 2011), which is also one of the reasons for generating singular values. Therefore, the subsequent analysis should also use grassland type as one of the independent variables to conduct correlation analysis. To improve the accuracy of the model, we should eliminate the singular value that cannot be traced to the source or if the reason for the traceability is not reasonable.

3.2.2 Comparing ecosystem services value of grassland classification. As shown in Figure 5, the grassland classification with the highest ESV is mountain meadow, with a value of 4,839.04 (US\$/ha/year), and the lowest classification is alpine desert, with a value of 233.34 (US\$/ha/year), which is quite different. The value of each grassland classification is ranked from high to low: mountain meadow $>$ warm shrub grass $>$ hot shrub grass $>$ lowland meadow $>$ alpine grassland $>$ temperate grassland $>$ alpine meadow $>$ warm desert $>$ alpine desert. From this trend, it can be found that the ESV of azonal range is generally high, and the service value of desert grassland ecosystem is generally low, which is consistent with the research conclusions obtained by scholars such as Jiang et al. (2007).

\subsection{Explanation of independent variables}

In this study, we include six independent variables: ESV accounting method, grassland classification, grassland ecosystem service function, regional economic development, grassland

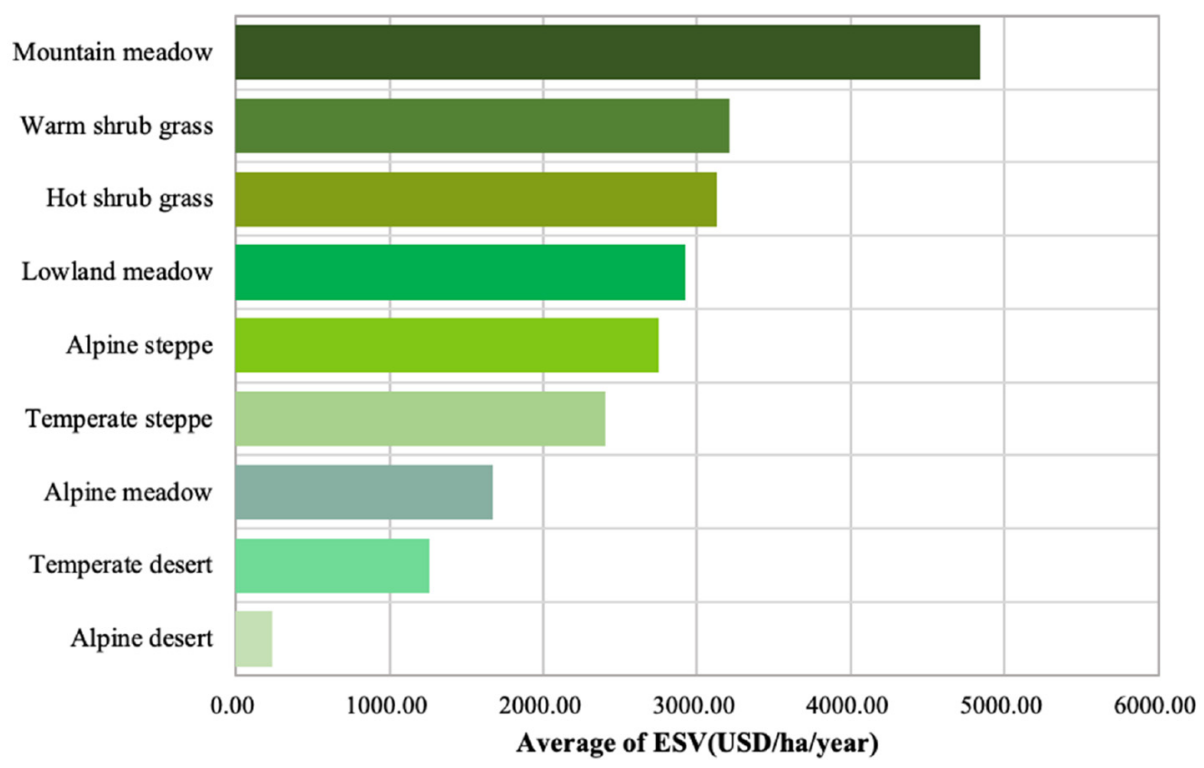

Figure 5.

Average ESV of different grassland types 
IJCCSM

12,5

626

characteristic and meteorological factors. We use GDP per capita to represent regional economic development (Zhang et al., 2015; Zhu et al., 2017); grassland area to represent grassland characteristics (Yan et al., 2019; Yang et al., 2017); and annual average temperature and annual average precipitation to represent climate change factors (Scheiter et al., 2019; Wang et al., 2016). Among all independent variables, three are numerical variables and dummy variables. Because there are many variables included in the model in this study, sometimes because of the high correlation between the explanatory variables, the multiple linear regression model cannot reasonably predict and explain. This phenomenon is called multicollinearity (Shrestha and Loomis, 2003). Therefore, to avoid the multicollinearity caused by the unreasonable setting of the dummy variable, we enter the type variable into the model in the form of assignment 0/1, and set the control group (Table 2).

\subsection{Estimation technique}

3.4.1 Single-factor screening. Generally, the modeling strategy for multi-factor regression is from "general-to-specific." In this study, referring to the practice of Chaikumbung et al. (2016), we first conduct a single-factor screening of the respective variables of the model. By comparing the size of Pearson correlation coefficient, we briefly judge the correlation between each dependent variable and independent variable. According to the absolute value of the correlation coefficient, it can be divided into three levels: very weak correlation $(|r|<0.3)$, weak correlation $(0.3<|r|<0.5)$, medium correlation $(0.5<|r|<0.7)$ and strong correlation $(|r|>0.7)$ (Bland and Altman, 1986), and then excluding independent variables that have no obvious correlation and no significant effect $(p>0.05)$.

3.4.2 Collinear diagnosis. To avoid multicollinearity, it is also necessary to eliminate outliers through collinearity diagnosis in the data analysis stage to reduce collinearity when setting variables. The method of collinearity diagnosis can judge the size of the variance expansion factor (VIF) and tolerance, and the larger the VIF, the stronger the collinearity. The tolerance is the reciprocal of the expansion coefficient of variance, and the value range is $0-1$. If the tolerance is smaller, the closer to 0 , the stronger the collinearity. Following Bergstrom and Taylor (2006) and Hedges et al. (1999), we can reasonably reduce the multicollinearity of the model by eliminating the variable with large VIF to improve the fitting accuracy.

3.4.3 Case diagnosis. In this study, the diagnosis of cases in the database is based on two aspects. On the one hand, we trace the singular values. After tracing, the observations with reasonable reasons for the singular values should be retained. Singular values that cannot be traced to the source or have unreasonable reasons and that differ from the standard value by 3 standard deviations should be eliminated. On the other hand, based on the definition of statistical value standardized residual, cases that do not meet the standard are eliminated. Following Yang et al. (2017), we exclude cases with an absolute value of standardized residuals larger than 2.5 to improve the fitting accuracy of the model.

\section{Meta-regression model results}

\subsection{Meta-interpretation model results}

We use WLSs and backward elimination to regress the equation to obtain two models. As shown in Table 3, Model 1 obtained by the WLS method has an $F$-value of 25.302 and an adjusted $R^{2}$ of 0.515 , indicating that Model 1 can explain the $51.5 \%$ variation in grassland ESV; and Model 2 obtained by the backward elimination method has an $F$-value of 29.433 and an adjusted $R^{2}$ of 0.556 , indicating that Model 2 can explain the $53.7 \%$ variation in grassland ESV. Comparing the results of the two models obtained by the two methods, in addition to the different control groups selected in the independent variable grassland 


\begin{tabular}{|c|c|c|c|c|c|}
\hline Variable & Description & Mean & SD & $\begin{array}{c}\text { No. of } \\
\text { observations }\end{array}$ & $\begin{array}{l}\text { Grassland } \\
\text { ecosystem }\end{array}$ \\
\hline $\begin{array}{l}\text { Dependent variable } \\
\mathrm{ESV}(\mathrm{USD} / \mathrm{ha} / \mathrm{year})\end{array}$ & Numeric variables (natural logarithm) & 6.279 & 2.101 & 564 & in China \\
\hline \multicolumn{6}{|l|}{ Independent variable } \\
\hline Per unit area method & Control group & 6.398 & 1.568 & 325 & \\
\hline Alternative cost method & Use alternative costing method: $1=$ yes; $0=$ otherwise & 6.065 & 3.035 & 95 & 627 \\
\hline Market value method & Use market value method: $1=$ yes; $0=$ otherwise & 6.749 & 1.958 & 48 & \\
\hline $\begin{array}{l}\text { Shadow engineering } \\
\text { method }\end{array}$ & $\begin{array}{l}\text { Use shadow engineering method: } 1=\text { yes; } 0= \\
\text { otherwise }\end{array}$ & 6.875 & 1.440 & 49 & \\
\hline Expense method & Use expense method: $1=$ yes; $0=$ otherwise & 5.178 & 2.349 & 22 & \\
\hline Opportunity cost method & $\begin{array}{l}\text { Use opportunity cost method: } 1=\text { yes; } 0= \\
\text { otherwise }\end{array}$ & 4.446 & 3.412 & 25 & \\
\hline Biodiversity protection & $\begin{array}{l}\text { Ecosystem service is biodiversity protection: } 1= \\
\text { yes; } 0=\text { otherwise }\end{array}$ & 7.380 & 0.987 & 46 & \\
\hline Livestock production & $\begin{array}{l}\text { Ecosystem service is livestock production: } 1=\text { yes; } \\
0=\text { otherwise }\end{array}$ & 6.108 & 1.523 & 59 & \\
\hline Water conservation & $\begin{array}{l}\text { Ecosystem service is water conservation: } 1=\text { yes; } \\
0=\text { otherwise }\end{array}$ & 6.926 & 1.316 & 77 & \\
\hline Soil retention & $\begin{array}{l}\text { Ecosystem service is soil retention: } 1=\text { yes; } \\
0=\text { otherwise }\end{array}$ & 6.314 & 2.760 & 67 & \\
\hline $\begin{array}{l}\text { Carbon fixation and } \\
\text { oxygen release }\end{array}$ & Control group & 7.492 & 1.192 & 83 & \\
\hline Climate regulation & $\begin{array}{l}\text { Ecosystem service is climate regulation: } 1 \text { = yes; } \\
0=\text { otherwise }\end{array}$ & 7.019 & 0.855 & 37 & \\
\hline Grass products & $\begin{array}{l}\text { Ecosystem service is grass products: } 1 \text { = yes; } \\
0=\text { otherwise }\end{array}$ & 5.113 & 1.546 & 54 & \\
\hline Nutrition cycle & $\begin{array}{l}\text { Ecosystem service is nutrition cycle: } 1 \text { = yes; } \\
0=\text { otherwise }\end{array}$ & 4.078 & 3.663 & 32 & \\
\hline Contaminant degradation & $\begin{array}{l}\text { Ecosystem service is contaminant degradation: } \\
1=\text { yes; } 0=\text { otherwise }\end{array}$ & 6.409 & 1.849 & 57 & \\
\hline Entertainment and culture & $\begin{array}{l}\text { Ecosystem service is Entertainment and culture: } \\
1=\text { yes; } 0=\text { otherwise }\end{array}$ & 4.458 & 1.781 & 52 & \\
\hline Temperate steppe & Control group & 6.357 & 2.093 & 173 & \\
\hline Alpine steppe & $\begin{array}{l}\text { Grassland classification is alpine steppe: } 1 \text { = yes; } \\
0=\text { otherwise }\end{array}$ & 6.356 & 2.021 & 62 & \\
\hline Temperate desert & $\begin{array}{l}\text { Grassland classification is temperate desert: } 1= \\
\text { yes; } 0=\text { otherwise }\end{array}$ & 5.331 & 2.153 & 110 & \\
\hline Alpine desert & $\begin{array}{l}\text { Grassland classification is alpine desert: } 1 \text { = yes; } \\
0=\text { otherwise }\end{array}$ & 5.770 & 1.200 & 6 & \\
\hline Warm shrub grass & $\begin{array}{l}\text { Grassland classification is warm shrub grass: } \\
1=\text { yes; } 0 \text { = otherwise }\end{array}$ & 7.491 & 1.355 & 16 & \\
\hline Hot shrub grass & $\begin{array}{l}\text { Grassland classification is hot shrub grass: } \\
1=\text { yes; } 0=\text { otherwise }\end{array}$ & 7.268 & 1.383 & 38 & \\
\hline Lowland meadow & $\begin{array}{l}\text { Grassland classification is lowland meadow: } \\
1=\text { yes; } 0=\text { otherwise }\end{array}$ & 6.156 & 1.935 & 43 & \\
\hline Mountain meadow & $\begin{array}{l}\text { Grassland classification is mountain meadow: } \\
1=\text { yes; } 0 \text { = otherwise }\end{array}$ & 7.006 & 2.131 & 64 & \\
\hline Alpine meadow & $\begin{array}{l}\text { Grassland classification is alpine meadow: } \\
1=\text { yes; } \\
0=\text { otherwise }\end{array}$ & 6.105 & 2.124 & 52 & \\
\hline Grassland area $\left(\mathrm{hm}^{2}\right)$ & Numeric variables (natural logarithm) & 12.912 & 3.058 & 564 & \\
\hline $\begin{array}{l}\text { GDP per capita }(\mathrm{CNY} / \\
\text { person) }\end{array}$ & Numeric variables (natural logarithm) & 10.267 & 0.436 & 564 & Explanation of \\
\hline Annual temperature $\left({ }^{\circ} \mathrm{C}\right)$ & Numeric variables (natural logarithm) & 9.757 & 2.313 & 564 & variables in Met \\
\hline Annual precipitation (mm) & Numeric variables (natural logarithm) & 11.438 & 3.217 & 564 & regression model \\
\hline
\end{tabular}




\section{IJCCSM \\ 12,5}

\begin{tabular}{|c|c|c|c|c|}
\hline Variable & $\begin{array}{c}\text { Model } 1 \text { (weighte } \\
\text { Unstandardizec } \\
\text { coefficients }\end{array}$ & squares) & \multicolumn{2}{|c|}{$\begin{array}{l}\text { Model } 2 \text { (backward elimination) } \\
\text { Unstandardized }\end{array}$} \\
\hline \multicolumn{5}{|l|}{ Accounting method } \\
\hline Constant term & $4.773 * *$ & 1.722 & 7.314 & 0.302 \\
\hline Per unit area method & \multicolumn{2}{|c|}{ Control group } & \multicolumn{2}{|c|}{ Control group } \\
\hline Alternative cost method & -0.314 & 0.268 & 0.200 & 0.197 \\
\hline Market value method & $1.356^{* * *}$ & 0.300 & $1.441^{* *}$ & 0.225 \\
\hline Shadow engineering method & -0.240 & 0.342 & \multicolumn{2}{|c|}{ Exclude } \\
\hline Expense method & -0.560 & 0.324 & $-0.851 * *$ & 0.300 \\
\hline Opportunity cost method & $-3.643^{* *}$ & 0.331 & $-3.793 * *$ & 0.306 \\
\hline \multicolumn{5}{|l|}{ Types of Grassland Ecosystem Services } \\
\hline Biodiversity protection & $3.874 * *$ & 0.328 & $0.803 * *$ & 0.236 \\
\hline Livestock production & $1.410 * *$ & 0.281 & $-1.152 * *$ & 0.231 \\
\hline Water conservation & $2.582^{* * *}$ & 0.312 & \multicolumn{2}{|c|}{ Control group } \\
\hline Soil retention & $2.530 * *$ & 0.303 & $0.563 *$ & 0.227 \\
\hline Carbon fixation and oxygen release & $3.205^{* * *}$ & 0.299 & $0.479 *$ & 0.218 \\
\hline Climate regulation & $2.711 * *$ & 0.342 & $0.179 *$ & 0.248 \\
\hline Grass products & 0.245 & 0.253 & $-2.202 * *$ & 0.229 \\
\hline Nutrition cycle & 0.145 & 0.360 & $-1.952 * *$ & 0.348 \\
\hline Contaminant degradation & $2.085^{* *}$ & 0.278 & -0.143 & 0.228 \\
\hline Entertainment and Culture & \multicolumn{2}{|c|}{ Control group } & $-2.475 * *$ & 0.234 \\
\hline \multicolumn{5}{|l|}{ Grassland classification } \\
\hline Temperate steppe & \multicolumn{2}{|c|}{ Control group } & \multicolumn{2}{|c|}{ Control group } \\
\hline Alpine steppe & -0.381 & 0.235 & -0.334 & 0.188 \\
\hline Temperate desert & $-1.320^{* * *}$ & 0.180 & $-0.969 * *$ & 0.160 \\
\hline Alpine desert & $-1.822^{* *}$ & 0.640 & $-1.676 * *$ & 0.525 \\
\hline Warm shrub grass & $1.019 *$ & 0.478 & $0.919 * *$ & 0.326 \\
\hline Hot shrub grass & 0.570 & 0.316 & $0.680^{* *}$ & 0.224 \\
\hline Lowland meadow & $-0.582^{*}$ & 0.261 & -0.252 & 0.219 \\
\hline Mountain meadow & 0.317 & 0.258 & $0.381 *$ & 0.192 \\
\hline Alpine meadow & -0.204 & 0.244 & -0.241 & 0.202 \\
\hline Grassland area $\left(\mathrm{hm}^{2}\right)$ & $-0.048^{*}$ & 0.024 & -0.021 & 0.019 \\
\hline GDP per capital (CNY/person) & 0.055 & 0.169 & \multicolumn{2}{|c|}{ Exclude } \\
\hline Annual temperature $\left({ }^{\circ} \mathrm{C}\right)$ & 0.097 & 0.094 & $0.176^{*}$ & 0.128 \\
\hline Annual precipitation (mm) & 0.544 & 0.179 & $0.043^{*}$ & 0.092 \\
\hline$F$-value & \multicolumn{2}{|c|}{25.302} & \multicolumn{2}{|c|}{29.433} \\
\hline Adjusted $R^{2}$ & \multicolumn{2}{|c|}{0.515} & \multicolumn{2}{|c|}{0.537} \\
\hline
\end{tabular}

Table 3.
Regression results of meta-interpretation model

Notes: ** and * show that the null hypothesis of the presence of unit root is rejected at $99 \%$ and $95 \%$ confidence levels, respectively

ecosystem functions, the coefficient direction, size and significance of the remaining independent variables are also basically the same. We should choose Model 2 with higher fitting accuracy as the explanation model.

Results reported in Table 3 show that temperature and precipitation have a positive significant effect on grassland ESV, which means climate changes may benefit for the grassland ecosystem. And according to the size of the regression coefficient, it can be obtained: Compared with the annual average precipitation, the annual average temperature has a greater impact on ESV. Figure 6(a) shows that the regression coefficients of the market value method, expense expenditure method and opportunity cost method are incredibly significant at $99 \%$ confidence level, and the remaining methods are not significant. From the 
point of view of unstandardized coefficients, the value estimated by the market value method is significantly higher than other value evaluation methods $(p<1 \%)$, which means that the use of the market value method will overestimate the grassland ESV. The value accounting result obtained by the opportunity cost method is significantly lower than other value evaluation methods $(p<1 \%)$, which means the grassland ESV is underestimated. Among them, the underestimation of grassland ESV is the most serious when using the opportunity cost method. This result may be that the evaluation of grassland value using the opportunity cost method is not comprehensive. For example, when the opportunity cost method is used to evaluate the soil conservation function, only the value of this grassland can be used for livestock production. This is incomplete, so it will cause an underestimation of the value of grassland ecosystem services.

Figure 6(b) shows that in the independent variable matrix of grassland ecosystem service types, except for the degradation function of pollutants, the values of other grassland ecosystem service types are statistically significantly different from the value of conserved water sources $(\phi<5 \%)$. Among them, biodiversity, livestock production, grass products,

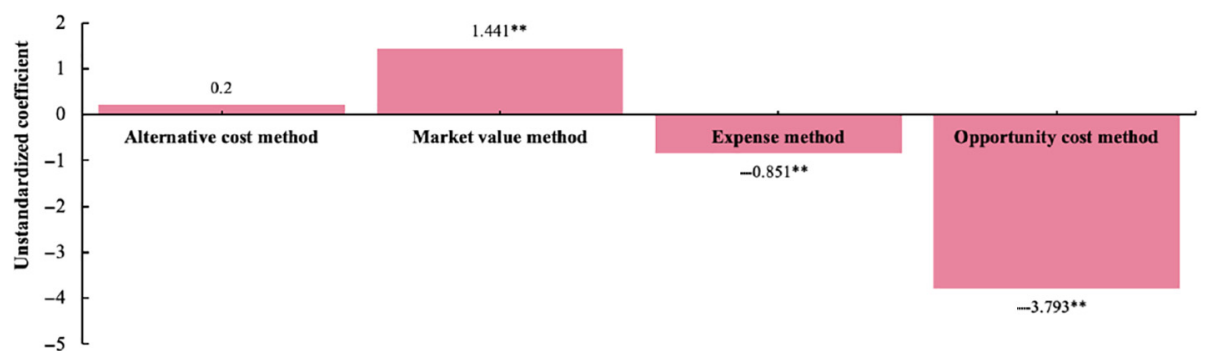

(a)

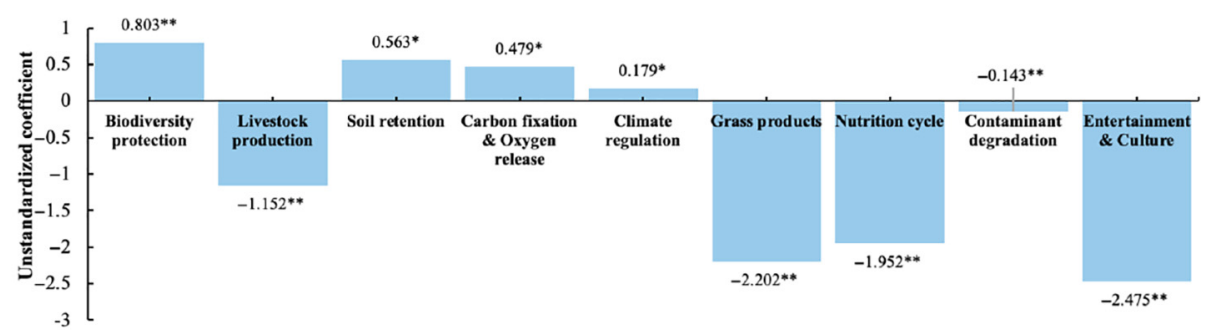

(b)

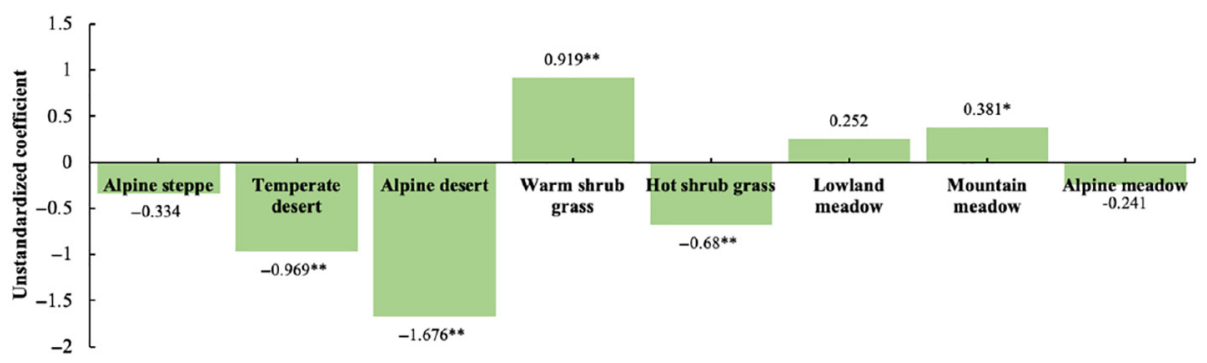

(c)

Figure 6.

Unstandardized coefficient of independent variables: (a) accounting method, (b) grassland ecosystem service type and (c) grassland classification 
IJCCSM 12,5

nutrient circulation and entertainment and culture have extremely significant differences compared with the value of water conservation $(p<1 \%)$. This result shows that under other conditions unchanged, the value of biodiversity protection; soil conservation; carbon fixation and oxygen release; and climate regulation functions are higher than the economic value of water conservation, and the highest value of biodiversity protection functions. The economic value of grass products, nutrient circulation, entertainment culture and animal husbandry production are all lower than the economic value of water conservation, of which entertainment culture has the lowest value.

Results reported in Figure 6(c) show that the unstandardized regression coefficients of warm shrub grass and tropical shrub grass are incredibly significant $(p<1 \%)$, the regression coefficient of mountain meadow is significantly positive $(p<5 \%)$ and the regression coefficient of warm desert and the alpine desert is exceptionally significant as negative $(p<1 \%)$; the remaining grassland types are not significant. Among them, the economic value of warm desert and alpine desert is significantly lower than the economic value per unit area of warm grassland $(\phi<1 \%)$. Warm shrub grass, hot shrub grass and mountain meadows are all non-zonal grasslands. The regression coefficients of these three types of grasslands are significantly positive $(p<5 \%)$, indicating that the economic value of non-zonal grasslands is higher than that of temperate grasslands. Among all the grassland types of the input grassland type independent variable matrix, the highest economic value per unit area is warm shrubs and the lowest is alpine desert, which is consistent with the results of Chen et al. (2012).

\subsection{Meta-prediction model results}

Based on the results of the meta-prediction model in Table 4, we can calculate that the grassland ecosystem service value in Qinghai province is 1,542.67 (US\$/ha/year). The specific calculation results are shown in Figure 7 and 8 . The results show that the order of each grassland function ESV from high to low is as follows: soil conservation $(25.4 \%)>$ carbon fixation and oxygen release $(16.47 \%)>$ pollutant degradation $(13.29 \%)>$ biodiversity protection $(12.63 \%)>$ livestock production $(10.22 \%)>$ climate regulation $(9.04 \%)>$ conservation of water sources $(7.48 \%)>$ grass products $(3.52 \%)>$ nutritional cycle $(1.35 \%)>$ entertainment culture $(0.59 \%)$. This result is different from the ranking obtained in the descriptive statistics. Compared with that, the result is more rigorous and statistically significant.

Among the grassland classifications in Qinghai province, the results show that the order of each grassland classification ESV from high to low is as follows: alpine meadow $>$ alpine steppe $>$ temperate steppe $>$ temperate desert $>$ lowland meadow $>$ alpine desert. It is interesting to note that the highest unit ESV is the alpine meadow, and the lowest is the alpine desert, which is just continuity of our previous findings. Such results may be related to the differences caused by the different productivity and adjustment ability of grassland classification. Despite through the single-factor screening and case diagnosis, the results are still consistent with the meta-interpretation model, indicating that the method is credible.

\subsection{Validity test results}

At the end, we have some diagnostic tests to check the validity of instruments used in the analysis, The validity test results of the meta-prediction model are shown in Table 5 . The validity test is carried out in four ways, all of which pass the test, indicating that the transfer error of the prediction model during the value transfer process is within $95 \%$ confidence level. There is no significant difference between the predicted value and the observed value. 


\begin{tabular}{lcc}
\hline Variable & Unstandardized coefficients & SD \\
\hline Content term & $8.060^{* * *}$ & 0.283 \\
Alternative cost method & $0.391^{*}$ & 0.170 \\
Market value method & $1.454^{* *}$ & 0.184 \\
Shadow engineering method & -0.015 & 0.193 \\
Expense method & $-1.186^{* *}$ & 0.257 \\
Opportunity cost method & $-6.513^{* *}$ & 0.334 \\
Biodiversity protection & -0.332 & 0.223 \\
Livestock production & $-1.997^{* * *}$ & 0.215 \\
Water conservation & $-0.840^{* *}$ & 0.203 \\
Carbon fixation and oxygen release & $-0.457^{*}$ & 0.200 \\
Climate regulation & $-0.666^{* *}$ & 0.226 \\
Grass products & $-3.063^{* *}$ & 0.213 \\
Nutrition cycle & $-2.960^{* *}$ & 0.301 \\
Contaminant degradation & $-0.672^{* * *}$ & 0.212 \\
Entertainment and culture & $-3.388^{* *}$ & 0.216 \\
Temperate steppe & 0.252 & 0.132 \\
Temperate desert & $-0.656^{* *}$ & 0.148 \\
Alpine desert & $-1.463^{* *}$ & 0.437 \\
Warm shrub grass & $0.965^{* *}$ & 0.284 \\
Hot shrub grass & $0.835^{* *}$ & 0.198 \\
Lowland meadow & $0.612^{* *}$ & 0.171 \\
Mountain meadow & 0.119 & 0.186 \\
Grassland area (hm ${ }^{2}$ ) & $-0.034^{*}$ & 0.016 \\
Annual temperature $\left({ }^{\circ} \mathrm{C}\right)$ & $0.158^{* *}$ & 0.128 \\
Annual precipitation $(\mathrm{mm})$ & 0.033 & 0.092 \\
F-value & 52.058 & \\
Adjusted $R^{2}$ & 0.684 & \\
& &
\end{tabular}

Notes: ** and * show that the null hypothesis of the presence of unit root is rejected at $99 \%$ and $95 \%$ confidence levels, respectively
Grassland ecosystem service value in China 631

Table 4. Regression results of meta-prediction model

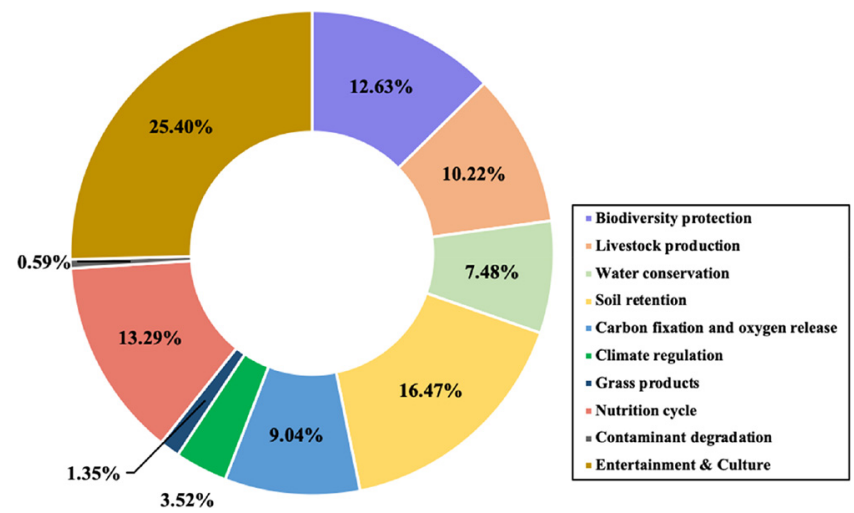

Figure 7.

Meta-transfer results of Qinghai province grassland functions 


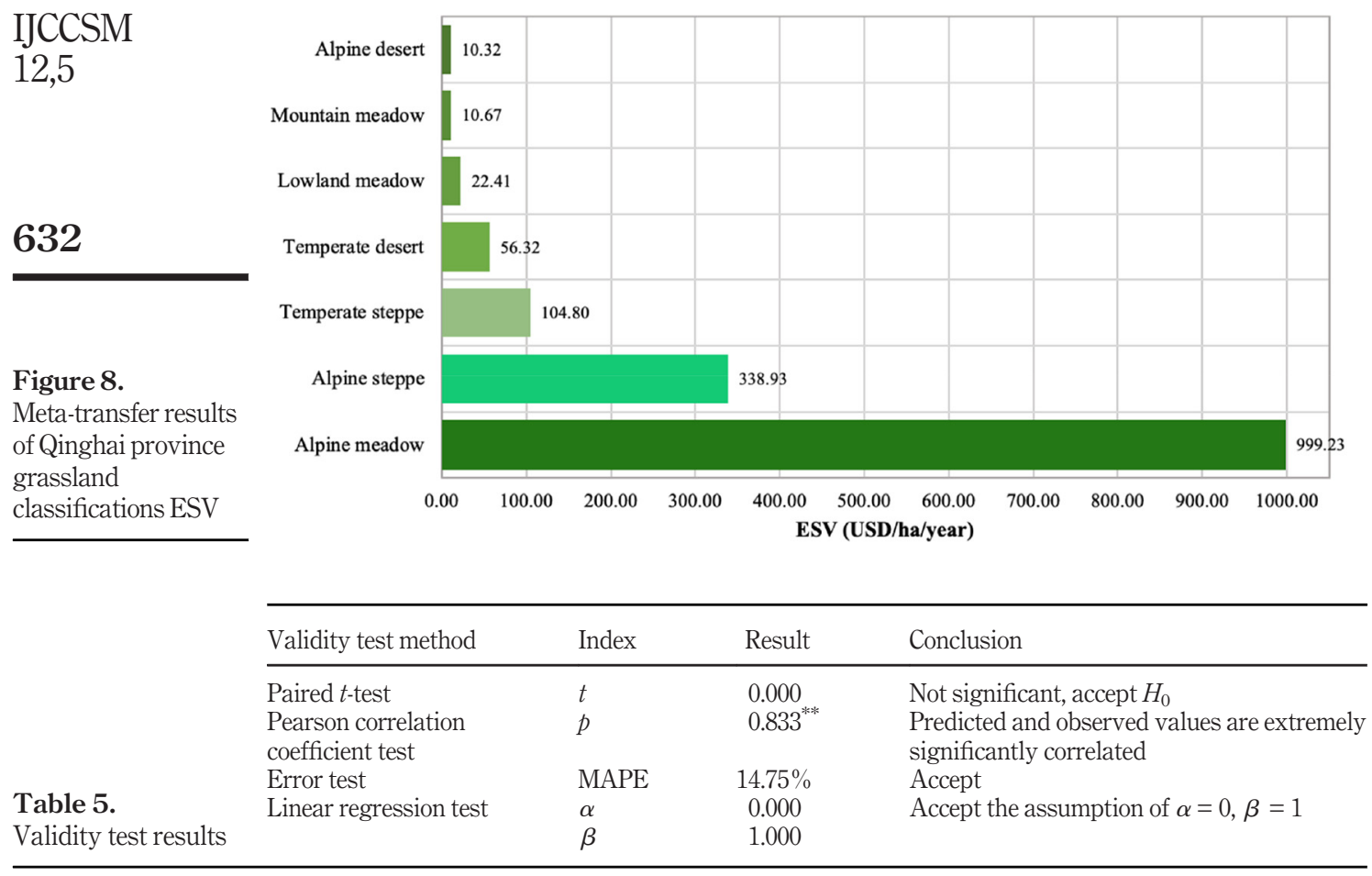

\section{Discussion}

Grassland ecosystems can provide multiple services, and there are individual differences between different types of service functions. Therefore, the economic value of grassland will also produce differences, thereby affecting the change in the total value of grassland. We find that entertainment and culture has the lowest value. The possible reason is that almost all of the entertainment culture value evaluation in the value transfer literature database adopts the travel expense method in the expense expenditure method (Zhang et al., 2015; Zhu et al., 2017). Some natural grassland areas have not developed tourism, or the tourism industry is not developed because of geographical location, so using the expense method to measure the entertainment cultural ESV has caused far underestimation.

In this study, we have demonstrated that whether in the sample literature or in the value transfer results, alpine meadows show the highest unit ESV, whereas alpine deserts show the lowest unit ESV. This can be explained by the higher productivity of alpine meadows, so the value of livestock production provided is higher than that of desert grasslands with low stocking capacity, and the aboveground biomass of meadow grasslands is also more abundant. The functional value of water conservation and even grass products is generally high (Nelson et al., 2013; Sala et al., 2017), which has an impact on the total ESV of different types of grasslands. This suggests that the government's protection of grasslands with high ESV is as important as the restoration of the environment.

Any climate can be classified based on temperature and precipitation (Geiger, 1954; Koppen, 1918), and vegetation in arid and semiarid areas is usually influenced by air temperature and precipitation (Wang et al., 2016). The two climate variables, temperature 
and precipitation, are the main focus of this paper. The positive sign of the coefficient of temperature and precipitation shows that climate factors affect grassland ESV positively. Zhu et al. (2015) believed the rise of ESV in Three-River Headwaters region was caused by climate and human activities, which is continuity of our findings. This may be because of the increase of grassland productivity under the background of global warming and humidification (Montoya and Raffaelli, 2010; Schroter et al., 2005), thereby achieving the effect of increasing grassland ESV. Compared with Wang et al. (2016), the results of this study are somewhat different. There are two main reasons. The first reason is the difference in the study area. The second reason is that the influence of human activities cannot be inputted as an independent variable in the model because of the difference in the quality of the data obtained in this study. Therefore, when considering the impact of climate change on ESV, the interference of human activities cannot be stripped away. Because of the limitations of the meta-interpretation model, this can only explain the past situation and cannot make predictions about future scenarios. Meta-analysis is based on linear relation, which is not that suitable for climate change, as it is relatively complicated. Therefore, a more accurate model to reflect the relation between climate change and ecosystem service value is needed. Different climate factors have different influences on the ecosystem and are related to the combination of water and heat. It is also an issue to be considered in future research.

The limitations of this study exist in three aspects. First, according to the sample literature selected by the meta-database, because of geographical factors such as rain and heat conditions, altitude and temperature, the distribution of grassland resources in China is zonal. The grassland types evaluated by the literature is mainly concentrated in typical grasslands, meadow grasslands, alpine grasslands and other areas. Most of the research sites are in the Inner Mongolia Plain, Northeast Plain and Qinghai-Tibet Plateau, while there are few studies in Xinjiang and South China. Because the number of grassland types in the database is not uniform, the impact of grassland type on the value of dependent variable cannot be fully explained. Second, the quality of the empirical research literature obtained by the screening is uneven and cannot be discerned only from the data level, which makes the comparability of the research results of different kinds of literature lower. Although the price parameter is adjusted, it is difficult to eliminate the influence of the time factor. For this situation, the sample information of the database is continuously expanded and updated to establish a long-term value transfer model of grassland ecosystem services. Because the value-transfer method is economically friendly, convenient and time-saving, it has positive significance for country's natural resource asset accounting. Third, the statistical data of policy land and grassland resources need to be used in the transfer of value, but the published statistical books can often be retrieved with a time lag. Therefore, if further study can combine GIS technology with the meta-regression model, the reliability and value transfer accuracy would be improved.

\section{Conclusions}

Based on the meta-regression interpretation model, analyze and explain the variables in the model, we find that the evaluation methods, types of ecosystem service functions, climate factors and types of grasslands can influence grassland ESV significantly. For the whole sample case in this study, there was a positive correlation between grassland ESV and climate factors. Based on the meta-regression prediction model, we calculate that the grassland ESV in Qinghai province is 1,542.67 (US\$/ha/year). The order of each grassland function ESV from high to low is as follows: soil conservation $(25.4 \%)>$ carbon fixation and oxygen release $(16.47 \%)>$ pollutant degradation $(13.29 \%)>$ biodiversity protection 
IJCCSM

12,5

634

$(12.63 \%)>$ livestock production $(10.22 \%)>$ climate regulation $(9.04 \%)>$ conservation of water sources $(7.48 \%)>$ grass products $(3.52 \%)>$ nutritional cycle $(1.35 \%)>$ entertainment culture $(0.59 \%)$. Additionally, the highest unit ESV is the alpine meadow, and the lowest is the alpine desert. Results of this study provide theoretical support for the future research of accounting grassland resources to promote the sustainable development of grassland ecosystems.

The plateau grassland greenness gained improvement under climate warming and wetting during the past 30 years, especially in Qinghai province. Temperature increased significantly with a warming magnitude of more than $1.5^{\circ} \mathrm{C}$ over the plateau grassland. In this article, we explained the relationship between climate change and grassland. The influence of climate change on ecosystem service value was studied through meta-analysis of ESV and air temperature and precipitation here. Furthermore, according to the size of the regression coefficient, the following can be obtained: compared with the annual average precipitation, the annual average temperature has a more significant impact on ESV. It can reveal the positive correlation between grassland ESV and climate factors from 2001 to 2019.

The findings contribute to policy implications enlightening adaptation planning at multiscales with knowledge of critical factors, which enhance grassland region adaptive capacity to reduce climate change vulnerability. It also provides a comprehensive approach to improve understanding of ecological asset accounting that can be conducive to the sustainable use of grassland resources. From the government level, the "Action Plan for Establishing a Market-oriented and Diversified Ecological Protection and Compensation Mechanism" jointly issued by the National Development and Reform Commission and other nine ministries has begun to financialize and market ecological assets. The plan mentions that a market-oriented and diversified ecological protection compensation mechanism will be initially established in 2020 . Under this mechanism, the enthusiasm of the whole society to participate in ecological protection can be effectively promoted. Therefore, it is foreseeable that, as a valuable ecological asset, the value-accounting method of grassland will gradually be refined and widely used, and the grassland ESV will be paid more attention. Finally, the ultimate goal of this study is to hope that the research results can provide a theoretical basis for the sustainable development of grassland resources and improve the grassland ESV. To achieve this goal, it also requires the participation of enterprises, the public and the government .

\section{References}

Bagstad, K.J., Johnson, G.W., Voigt, B. and Villa, F. (2013), "Spatial dynamics of ecosystem service flows: a comprehensive approach to quantifying actual services", Ecosystem Services, Vol. 4 No. 1, pp. 117-125.

Bergstrom, J.C. and Taylor, L.O. (2006), "Using meta-analysis for benefits transfer: theory and practice”, Ecological Economics, Vol. 60 No. 2, pp. 351-360.

Bland, J.M. and Altman, D.G. (1986), "Statistical methods for assessing agreement between two methods of clinical measurement", The Lancet, Vol. 327 No. 8476, pp. 307-310.

Brander, L.M., Wagtendonk, A.J., Hussain, S.S., Mcvittie, A., Verburg, P.H., De Groot, R.S. and Van Der Ploeg, S. (2012), "Ecosystem service values for mangroves in southeast asia: a metaanalysis and value transfer application", Ecosystem Services, Vol. 1 No. 1, pp. 62-69.

Cairns, J. Jr (1997), "Protecting the delivery of ecosystem services", Ecosystem Health, Vol. 3 No. 3, pp. $185-194$. 
Chaikumbung, M., Doucouliagos, H. and Scarborough, H. (2016), “The economic value of wetlands in developing countries: a meta-regression analysis", Ecological Economics, Vol. 124, pp. 164-174.

Chen, C., Tao, Z., Wang, H. and Dai, J. (2012), "Ecosystem service assessment of grasslands in the Sanjiangyuan region", Progress in Geography, Vol. 31 No. 7, pp. 978-984.

Costanza, R., Darge, R., Degroot, R., Farber, S., Grasso, M., Hannon, B., Limburg, K., Naeem, S., Oneill, R.V., Paruelo, J., Raskin, R.G., Sutton, P. and Vandenbelt, M. (1997), “The value of the world's ecosystem services and natural Capital", Nature, Vol. 387 No. 6630, pp. 253-260.

Daily, G.C. (1997), Nature's Services: societal Dependence on Natural Ecosystems, Island Press, Washington, DC.

Du, J. and Yu, D. (2018), "Impacts of climate change and human activities on net primary productivity of grassland in agro-pastoral transitional zone in Northern China", Journal of Beiing Normal University (Natural Science), Vol. 54 No. 3, pp. 365-372.

Duarte, G.T., Santos, P.M., Cornelissen, T.G., Ribeiro, M.C. and Paglia, A.P. (2018), "The effects of landscape patterns on ecosystem services: meta-analyses of landscape services", Landscape Ecology, Vol. 33 No. 8, pp. 1247-1257.

Fleiss, J.L. and Gross, A.J. (1991), "Meta-analysis in epidemiology, with special reference to studies of the association between exposure to environmental Tobacco-Smoke and Lung-Cancer - a critique", Journal of Clinical Epidemiology, Vol. 44 No. 2, pp. 127-139.

Gao, Y. and Lin, H. (2014), "The prospects for rangeland ecosystem services evaluation", Acta Prataculturae Sinica, Vol. 23 No. 3, pp. 290-301.

Garson, G.D. (2013), Weighted Least Squares Regression, Statistical Publishing Associates, Asheboro, NC.

Geiger, R. (1954), "Landolt-Bornstein-Zahlenwerte und FunktionenausPhysik, chemie, astronomie, geophysik und technik", Ch. Klassifikation Der Klimatenach W. Koppen, Vol. 3 No. 1, pp. 603-607.

Ghermandi, A., Van Den Bergh, J.C.J.M., Brander, L.M., De Groot, H.L.F. and Nunes, P.A.L.D. (2010), "Values of natural and human-made wetlands: a meta-analysis", Water Resources Research, Vol. 46 No. 1210.1029/2010WR009071.

Hedges, L.V., Gurevitch, J. and Curtis, P.S. (1999), “The meta-analysis of response ratios in experimental ecology", Ecology, Vol. 80 No. 4, pp. 1150-1156.

Intergovernmental Science-Policy Platform on Biodiversity and Ecosystem Services (2019), "Summary for policymakers of the global assessment report on biodiversity and ecosystem services", available at: https://doi.org/10.5281/zenodo.3553579 (accessed 25 November 2019).

Jiang, L., Qin, Z., Xie, W., Wang, R., Xu, B. and Lu, Q. (2007), "Estimation of grassland ecosystem services value of China using remote sensing data", Journal of Natural Resources, Vol. 22 No. 2, pp. 161-170.

Johnston, R.J. and Rosenberger, R.S. (2010), "Methods, trends and controversies in contemporary benefit transfer", Journal of Economic Surveys, Vol. 24 No. 3, pp. 479-510.

Kolstad, C.D. (2000), Environmental Economics, Oxford University Press, New York, NY, Oxford.

Koppen, W. (1918), "Classification of the climate according to temperature, humidity and course of the year", Petermanns Mitteilungen, Vol. 64, pp. 243-248.

Li, Q., Ao, C., Yuan, W. and Gao, Q. (2018), “A meta-analysis of wetland CVM studies in China”, Resources Science, Vol. 40 No. 8, pp. 1634-1644.

Maalouf, J.P., Le Bagousse-Pinguet, Y., Marchand, L., Bâchelier, E., Touzard, B. and Michalet, R. (2012), "Integrating climate change into calcareous grassland management", Journal of Applied Ecology, Vol. 49 No. 4, pp. 795-802.

Millenium Ecosystem Assessment (2005), Ecosystems and Human Well-Being: Synthesis, Island Press, Washington, DC. 
IJCCSM 12,5

Miller, M.E., Belote, R.T., Bowker, M.A. and Garman, S.L. (2011), “Alternative states of a semiarid grassland ecosystem: implications for ecosystem services", Ecosphere, Vol. 2 No. 5.

Moeltner, K., Boyle, K.J. and Paterson, R.W. (2007), "Meta-analysis and benefit transfer for resource valuation-addressing classical challenges with bayesian modeling", Journal of Environmental Economics and Management, Vol. 53 No. 2, pp. 250-269.

Montoya, J.M. and Raffaelli, D. (2010), "The effects of climate change on biotic interactions and ecosystem services", Philosophical Transactions of the Royal Society B: Biological Sciences, Vol. 365 No. 1549, pp. 2011-2011.

Nelson, E.J., Kareiva, P., Ruckelshaus, M., Arkema, K., Geller, G., Girvetz, E., Goodrich, D., Matzek, V., Pinsky, M., Reid, W., Saunders, M., Semmens, D. and Tallis, H. (2013), "Climate change's impact on key ecosystem services and the human well-being they support in the US", Frontiers in Ecology and the Environment, Vol. 11 No. 9, pp. 483-493.

Ning, J., Jin, J., Kuang, F., Wan, X., Zhang, C. and Guan, T. (2019), "The valuation of grassland ecosystem services in Inner Mongolia of China and its spatial differences", Sustainability, Vol. 11 No. 24 .

Qi, X., Huang, X. and Lai, L. (2018), “An empirical study of meta-analytical value transfer of forest ecosystem services in China”, Scientia Geographica Sinica, Vol. 38 No. 4, pp. 522-530.

Rosenberger, R.S. and Loomis, J.B. (2001), "Benefit transfer of outdoor recreation use values: a technical document supporting the Forest service strategic plan (2000 revision)", General Technical Report-Rocky Mountain Research Station, USDA Forest Service, No RMRS-GTR-72.

Sala, O.E., Yahdjian, L., Havstad, K. and Aguiar, M.R. (2017), "Rangeland ecosystem services: nature's supply and humans' demand", in Briske, D.D. (Ed.), Rangeland Systems: Processes, Management and Challenges Springer Series on Environmental Management, pp. 467-489.

Salem, M.E. and Mercer, D.E. (2012), "The economic value of mangroves: a meta-analysis", Sustainability, Vol. 4 No. 3, pp. 359-382.

Sándor, A.D. and Domşa, C. (2018), "Climate change, predictive modelling and grassland specialists: assessing impacts of changing climate on the long-term conservation of lesser grey shrikes (lanius minor) in Romania", Journal of Ornithology, Vol. 159 No. 2, pp. 413-424.

Scheiter, S., Schulte, J., Pfeiffer, M., Martens, C., Erasmus, B.F.N. and Twine, W.C. (2019), "How does climate change influence the economic value of ecosystem services in savanna rangelands?", Ecological Economics, Vol. 157, pp. 342-356.

Schirpke, U., Kohler, M., Leitinger, G., Fontana, V., Tasser, E. and Tappeiner, U. (2017), "Future impacts of changing land-use and climate on ecosystem services of mountain grassland and their resilience", Ecosystem Services, Vol. 26, pp. 79-94.

Schroter, D., Cramer, W., Leemans, R., Prentice, I.C., Araujo, M.B., Arnell, N.W., Bondeau, A., Bugmann, H., Carter, T.R., Gracia, C.A., De La Vega-Leinert, A.C., Erhard, M., Ewert, F., Glendining, M., House, J.I., Kankaanpaa, S., Klein, R.J.T., Lavorel, S., Lindner, M., Metzger, M.J., Meyer, J., Mitchell, T.D., Reginster, I., Rounsevell, M., Sabate, S., Sitch, S., Smith, B., Smith, J., Smith, P., Sykes, M.T., Thonicke, K., Thuiller, W., Tuck, G., Zaehle, S. and Zierl, B. (2005), "Ecosystem service supply and vulnerability to global change in Europe", Science, Vol. 310 No. 5752, pp. 1333-1337.

Shrestha, R.K. and Loomis, J.B. (2003), "Meta-analytic benefit transfer of outdoor recreation economic values: testing out-of-sample convergent validity", Environmental and Resource Economics, Vol. 25 No. 1, pp. 79-100.

Sun, B., Cui, L., Li, W., Kang, X. and Zhang, M. (2018), “A review of spatial-scale transformation in wetland ecosystem service evaluation”, Acta Ecologica Sinica, Vol. 38 No. 8, pp. 2607-2615.

Tao, J., Zhang, Y., Dong, J., Fu, Y., Zhu, J., Zhang, G., Jiang, Y., Tian, L., Zhang, X., Zhang, T. and Xi, Y. (2015), "Elevation-dependent relationships between climate change and grassland vegetation variation across the Qinghai-Xizang Plateau", International Journal of Climatology, Vol. 35 No. 7, pp. 1638-1647. 
Wang, H., Zhou, S.L., Li, X.B., Liu, H.H., Chi, D.K. and Xu, K.K. (2016), "The influence of climate change and human activities on ecosystem service value", Ecological Engineering, Vol. 87, pp. 224-239.

Watson, L., Straatsma, M.W., Wanders, N., Verstegen, J.A., Jong, S. M, D. and Karssenberg, D. (2020), "Global ecosystem service values in climate class transitions", Environmental Research Letters, Vol. 15 No. 2, p. 15.

Xie, G., Lu, C., Xiao, Y. and Zheng, D. (2003), “The economic evaluation of grassland ecosystem services in Qinghai-Tibet Plateau”, Journal of Mountain Science, Vol. 21 No. 1, pp. 50-55.

Xu, X., Huang, X. and Zhao, H. (2019), "Meta-regression on the benefit transfer of water resources in

Grassland ecosystem service value in China

Yan, Y., Yao, L., Lang, L. and Zhao, M. (2019), "Revaluation of ecosystem services in inland river basins of China: based on meta-regression analysis", Acta Geographica Sinica, Vol. 74 No. 5, pp. 1040-1057.

Yang, L., Kong, F-L., Xi, M., Li, Y. and Wang, S. (2017), "Ecosystem services assessment of wetlands in qingdao based on meta-analysis", Shengtaixue Zazhi, Vol. 36 No. 4, pp. 1038-1046.

Zhang, L., Li, X., Zhou, D. and Zhang, Y. (2015), "An empirical study of meta-analytical value transfer of lake and marsh ecosystem services in China”, Acta Ecologica Sinica, Vol. 35 No. 16, pp. $5507-5517$.

Zhang, Y., Liu, Y., Zhu, W. and Li, S. (2016), "Ecosystem service valuation and value transfer of land use types:a comprehensive meta-analysis of the literature", Acta Scientiarum Naturalium Universitatis Pekinensis, Vol. 52 No. 3, pp. 493-504.

Zhao, L. and Wang, E. (2011), "An overview of the applications of benefit transfer method in recreation resources economic valuation”, China Population, Resources and Environment, Vol. 21 No. 12, pp. 490-495.

Zhou, J., Wu, J. and Yu, Z. (2016), "Reassessment of the studies on biodiversity valuation: inspired by meta-analysis", Journal of Ecology and Rural Environment, Vol. 32 No. 1, pp. 143-149.

Zhu, X., Zhang, J., Cheng, M. and Xu, Q. (2017), "A study on transfer of ecosystem service values in mining cities by meta-analysis", Journal of Natural Resources, Vol. 32 No. 3, pp. 434-448.

Zhu, J., Zhou, Y., Wang, S., Wang, L., Wang, F., Liu, W. and Guo, B. (2015), "Multicriteria decision analysis for monitoring ecosystem service function of the three-river headwaters region of the Qinghai-Tibet Plateau, China”, Environmental Monitoring and Assessment, Vol. 187 No. 6.

\section{Author affiliations}

Binyue Kang, College of Grassland Science and Technology, China Agricultural University, Beijing, China and College of Environmental Science and Engineering, Nankai University, Tianjin, China

Qiuyu Shao, School of Economics and Management, University of Science and Technology, Beijing, China, and

Hengkang $\mathrm{Xu}$, Fengyan Jiang, Xiaoting Wei and Xinqing Shao, College of Grass Science and Technology, China Agricultural University, Beijing, China

\section{Corresponding author}

Xinqing Shao can be contacted at: shaoxinqing@163.com

For instructions on how to order reprints of this article, please visit our website:

www.emeraldgrouppublishing.com/licensing/reprints.htm

Or contact us for further details: permissions@emeraldinsight.com 